УДК 546.98

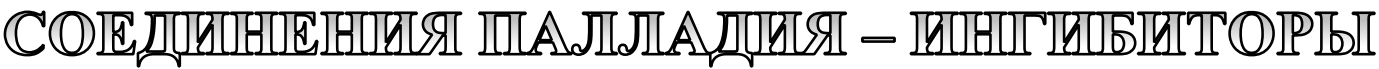

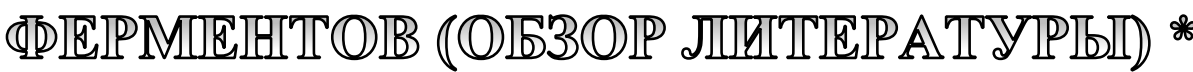

\author{
М.С. Денисов, Институт технической химии УрО РАН
}

\section{Для цитирования:}

Денисов М.С. Соединения палладия - ингибиторы ферментов (обзор литературы) // Вестник Пермского федерального исследовательского центра. - 2021. - № 4. - С. 6-18. https://doi.org/10.7242/2658-705X/2021.4.1

В настоящем обзоре собраны литературные данные 1969-2021 гг., направленные на изучение координационного окружения палладия в транс-координированных, бидентатных N, S, фросфиновых и иминофенольных комплексных соединениях металла, а также селективного воздействия палладия при ингибировании ферментативной активности и возможного проявления его токсичности. Показано, что соединения палладия ингибируют ферменты, участвующие в патогенезе ряда заболеваний, таких как болезнь Альцгеймера, Паркинсона, атеросклероз и сахарный диабет второго типа. Соединения палладия могут применяться в таргетной терапии рака не только по механизму воздействия на молекулу ДНК, но и в качестве ингибиторов опухолевых ферментов. Также известно, что соединения палладия могут использоваться в качестве ингибиторов ферментов вирусов ВИЧ-1, SARS-CoV-2, возбудителя сонной болезни, гнилостных бактерий и других микроорганизмов. В то же время некоторые комплексы палладия являются потенциальными токсинами и аллергенами из-за ингибирования ферментов, необходимых для нормального метаболизма.

В данном обзоре обращено особое внимание на работы ученых Пермского федерального исследовательского центра УрО РАН, посвященные ингибированию моноаминоксидаз, участвующих в развитии болезни Паркинсона. Нами отмечено, что поиск новых комплексов палладия является перспективным направлением для биомедицины.

Ключевые слова: абиогенез, генетический код, протобиомономеры, свойства аминокислот и нуклеотидных оснований.

\section{Введение}

Соединения платиновых металлов, в первую очередь платины $(\mathrm{Pt})$, рутения $(\mathrm{Ru})$ и палладия $(\mathrm{Pd})$, демонстрируют различную биологическую активность по механизмам воздействия на молекулу
ДНК и при ингибировании ферментов. Открытие противоопухолевых свойств соединения $\mathrm{Pt}$ - цисплатина [cis- $\mathrm{Pt}\left(\mathrm{NH}_{3}\right)_{2} \mathrm{Cl}_{2}$ ] в 1969 г. и его последующее внедрение в клиническую практику простимулировало поиск биологически активных комплексов

\footnotetext{
* Исследование выполнено при финансовой поддержке РФФИ и Министерства образования и науки Пермского края в рамках научного проекта № 19-43-590003.
} 
платиновых металлов [1-2]. В настоящее время цисплатин используется при химиотерапевтическом лечении злокачественных новообразований: метастатических тестикулярных опухолей, метастатических опухолей яичника и запущенной стадии рака мочевого пузыря [3].

Основной биологической мишенью для цисплатина служит ДНК, но возможно связывание вещества с другими мишенями, такими как белки, РНК, мембранные фосфолипиды, микрофиламенты и тиолсодержащие пептиды [4], что позволяет предположить применение цисплатина, в том числе и для лечения заболеваний, отличных от опухолей. Однако данное вещество обладает низкой растворимостью и высокой токсичностью, что препятствует широкому медицинскому применению [2]. В связи с этим поиск других соединений платинных металлов, лишенных недостатков цисплатина, является перспективным направлением для биомедицины. В частности, по литературным данным известно, что соединения палладия обладают низкой токсичностью (например, в опыте на крысах полулетальная доза $\mathrm{LD}_{50}$ для $\mathrm{PdCl}_{2}$ составляет 2,7 г/кг, которая близка к $\mathrm{LD}_{50}$ для $\mathrm{KCl}$ $(2,6$ г/кг), использованного в качестве препарата сравнения) [5].

Исторически сложилось, что ферменты, участвующие в метаболизме злокачественных новообразований, являются удобными мишенями для разработки лекарств на основе металлов [6-9]. В то же время известно, что ингибирование ферментативной активности при заболеваниях различной этиологии может быть ключевым аспектом для терапевтического лечения.

Среди платиновых металлов в этом направлении больших успехов достигла химия соединений рутения. Например, соединения $\mathrm{Ru}$ предложены для терапии болезни Альцгеймера по механизму ингибирования ацетилхолинэстеразы [10], сахарного диабета по механизму ингибирования тирозинфосфатазы [11] и болезни Паркинсона по механизму воздействия на митохондрии дофаминергических нейро- нов [12,13]. Существует ряд обзоров, посвящённых ингибированию ферментов комплексами металлов [2, 14-18], но отсутствуют обзорные работы об ингибировании ферментов комплексами палладия.

Существующие обзоры биологически активных комплексов Pd посвящены противораковому действию преимущественно по механизму воздействия на ДНК [19-24]. Из-за химического сходства палладия и платины предполагается, что комплексы Pd проявляют противораковую активность по аналогии с цисплатином. Также известно, что у опухолевых линий не наблюдается перекрёстной резистентности между соединениями $\mathrm{Pd}$ и $\mathrm{Pt}[25,26]$ (соединения $\mathrm{Pd}$ проявляют цитотоксическую активность на клеточных линиях, не восприимчивых к соединениям Pt), на основании чего можно предположить, что комплексы Pd имеют другие мишени в опухолевых клетках.

Как правило, в большинстве исследований отмечается биологическая активность комплексов Pd без определения мишени, так как поиск фермента-мишени в опухолевой или иной (например, бактериальной) клетке затруднителен. Например, авторы работы [27] предполагают, что антибактериальная активность их комплексов $\mathrm{Pd}$ связана с окислением клеточной стенки, ингибированием фермента ДНК-гиразы и прямым взаимодействием с молекулой ДНК; но мишень не была доказана ни экспериментально, ни численно (молекулярный докинг).

В настоящем обзоре мы собрали работы, в которых определены ферменты мишени комплексов $\mathrm{Pd}$, классифицированные исходя из их химической структуры. На схемах приведены структуры наиболее активных комплексов Pd.

\section{Неорганические комплексы}

Для неорганических комплексов палладия известны две устойчивые степени окисления: II и IV, в которых Pd способен образовывать комплексы $\mathrm{Na}_{2}\left[\mathrm{PdCl}_{4}\right]$ и $\mathrm{Na}_{2}\left[\mathrm{PdCl}_{6}\right]$, соответственно; что отлично от органических комплексов $\mathrm{Pd}$, в кото- 
рых устойчивой степенью окисления является II, a IV встречается относительно редко. В работе [28] показана способность комплекса $\mathrm{Na}_{2}\left[\mathrm{PdCl}_{4}\right]$ ингибировать $\mathrm{Na}^{+} / \mathrm{K}^{+}$-АТФазу. Мембранный фермент $\mathrm{Na}^{+} / \mathrm{K}^{+}$-АТФаза осуществляет транспорт ионов натрия и калия, используя энергию гидролиза АТФ [29]. Замена противоиона в комплексе $\mathrm{Na}_{2}\left[\mathrm{PdCl}_{4}\right]$ позволяет получить комплекс $\mathrm{K}_{2}\left[\mathrm{PdCl}_{4}\right]$, являющийся ингибитором $\mathrm{Ca}^{2+} / \mathrm{Mg}^{2+}$-АТФазы саркоплазматического ретикулума скелетной мускулатуры [30]. Предположено, что модификация обеих АТФаз осуществляется неорганическими соединениями палладия и платины по SH-группам [28], что может быть объяснением аллергических реакций у лиц, работающих с солями Pt [31]. Для $\mathrm{K}_{2}\left[\mathrm{PdCl}_{4}\right]$ выявлена способность ингибировать моноаминоксидазы (MAO) [32]. Известно, что ингибиторы $\mathrm{MAO,} \mathrm{которыми} \mathrm{являются} \mathrm{разагилин} \mathrm{и}$ моклобемид используются в терапии болезни Паркинсона $[3,33]$ и атипичной депрессии [3, 34], соответственно.

Таким образом, становится перспективным поиск ингибиторов МАО среди соединений Pd. Удаление побочной биологической активности (аллергенность и токсичность) с сохранением целевой (ингибирование МАО) активности неорганических соединений $\mathrm{Pd}$ может быть достигнуто заменой в комплексе Pd противоиона с неорганического на органический. В «ИТХ УрО РАН» получены ряды комплексов Pd 1-3, демонстрирующих МАО ингибирующую активность при отсутствии цитотоксической активности [35].

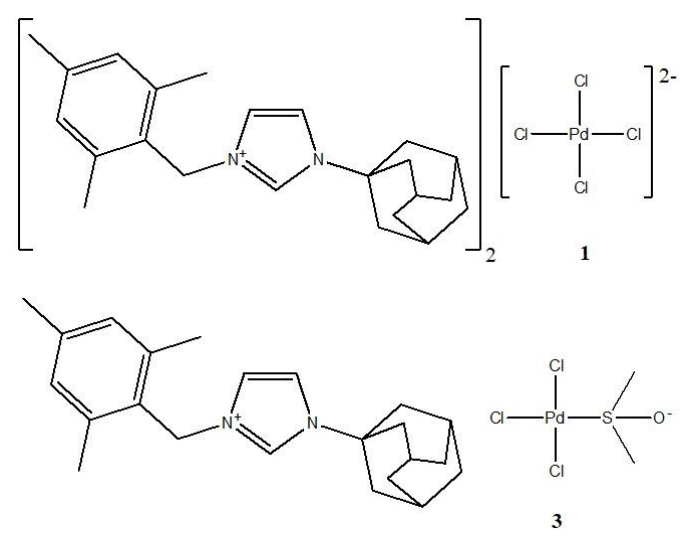

Ранее другой научной группой был описан механизм ингибирования МАО палладием [36], объясненный тем, что реакция превращения аминов, катализируемая МАО (метаболизм норадреналина, серотонина, дофамина и т.д.) идет через промежуточно образующиеся альдимины - Pd вступает в комплексообразование по NH-альдиминам и прерывает превращение аминов. Аналогичным методом замены противоиона получен комплекс $\mathrm{Pd} 4$, ингибирующий по механизму перехвата свободных радикалов липоксигеназу сои, являющуюся гомологом липоксигеназ млекопитающих, необходимых для окисления линоленовой кислоты [37], что делает соединение 4 перспективным для терапии атеросклероза, так как окисление жирных кислот изоэнзимами липоксигеназы определяют как часть патогенеза заболевания [38].

Соединения $\mathrm{Pd}^{\mathrm{IV}}$ в отличие от соединений $\mathrm{Pd}^{\mathrm{II}}$ пока еще не нашли биомедицинского применения. Комплексы $\mathrm{Na}_{2}\left[\mathrm{PdCl}_{6}\right]$ и $\left[\mathrm{NH}_{4}\right]_{2}\left[\mathrm{PdCl}_{6}\right]$ предложены для защиты древесины от гниения, так как способны ингибировать целлюлазу (фермент, гидролизующий целлюлозу), связываясь с SH-группами в активном центре фермента $[39,40]$. В связи с этим предполагается, что комплексы $\mathrm{Pd}^{\mathrm{IV}}$ могут быть ингибиторами ферментов болезнетворных бактерий и грибов.

\section{Транс-комплексы}

Для получения устойчивых транс-комплексов $\mathrm{Pd}^{\mathrm{II}}$ необходимы объемные монодентатные лиганды, так как из-за своих

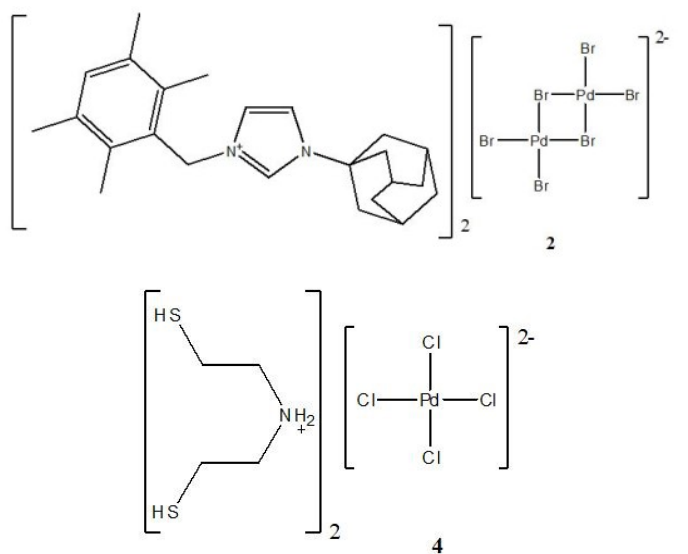


размеров эти лиганды минимизируют возможную изомеризацию в цүис-форму [41]. Указанному требованию соответствуют бензимидазольные PEPPSI-комплексы (PEPPSI - Pyridine Enhanced Precatalysts: Preparation, Stabilisation and Initiation) и их трифенилфосфиновые аналоги. В этих комплексах палладий, с одной стороны, координирован на N-гетероциклический карбен, полученный из солей имидазолия, или на трифенилфосфин, что обеспечивает огромный \% $\mathrm{V}_{\text {bar }}$ (доля сферы с металлом в центре, занятая лигандом) [42]. С другой стороны, в транс-положении к карбену или фосфину $\mathrm{Pd}$ координирован на уходящий N-лиганд (пиридиновый, аминовый, анилиновый азот) - примеры структур 5-12 приведены ниже. Синтез веществ 5-10 и множества иных комплексов $\mathrm{Pd}$, а также результаты исследований на предмет ингибирования различных ферментов изложены в работах [43-45]. В частности, комплексы 5 и 7 проявили повышенную ингибирующую активность в отношении разлагающих угольную кислоту ферментов (hCA I в случае 5 и hСA I и II в случае 7), ацетилхолинэстеразы (AChA) и бутирилхолинэстеразы (BChE); что делает вещества перспективными в терапии болезни Альцгеймера.

Действительно, у пациентов с болезнью Альцгеймера возникает дисбаланс между активностью эстераз: активность AChA не

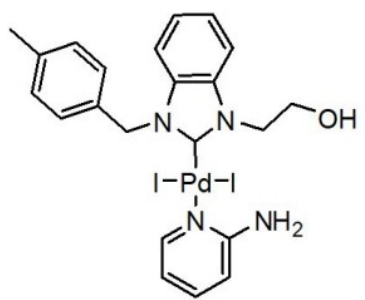

5

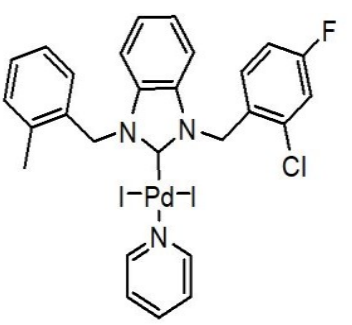

9

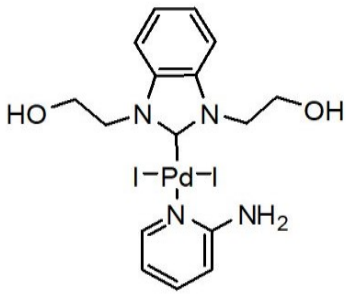

6

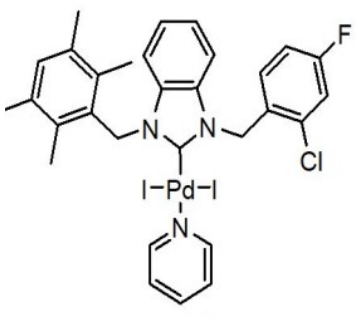

10

изменяется, а активность ВChE значительно возрастает. Таким образом, оба фермента, по-видимому, играют определенную роль в регуляции уровня ацетилхолина и считаются важными терапевтическими мишенями при лечении болезни Альцгеймера. В результате на поздних стадиях заболевания лучше ингибировать оба фермента вместо применения селективных ацетилхолинэстераз [46]. Комплексы 6 и 8 отличаются повышенной способностью ингибировать фермент углеводного обмена $\alpha$-гликозидазу, что является перспективным для терапии сахарного диабета второго типа. Комплексы 9 и 10 тоже являются ингибиторами как $\alpha$-гликозидазы, так и ацетилхолинэстеразы. У некоторых PEPPSI-комплексов выявлена способность ингибировать фермент serum paraoxonase and arylesterase 1 (РON1), в частности у комплекса 11 [47]. Из-за того, что физиологический субстрат фермента PON1 еще не ясен, нельзя исключать необходимость фермента для нормального метаболизма [48]. Тем не менее установлено, что именно PON1 осуществляет разложение параоксона (ингибитор $\mathrm{AChA}$ ), применявшегося для лечения глаукомы (в настоящее время не используется из-за токсичности [3]). Методом молекулярного докинга не удалось объяснить ингибирующую активность вещества 11 по отношению к PON1 [47].

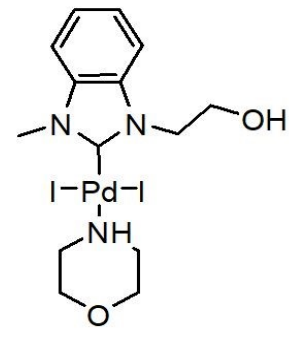

7

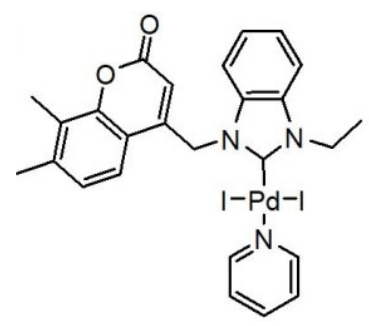

11<smiles>CCN1c2ccccc2N(CCO)C1[P+](Br)(Br)(Br)N1CCOCC1</smiles>

8<smiles></smiles>

12 
Транс-фосфиновый комплекс 12 ингибирует фермент углеводного обмена $\beta$-глюкуронидазу [49]. То, что недостаточность $\beta$-глюкуронидазы вызывает мукополисахаридоз VII типа [50], является вероятной проблемой для биомедицинского применения устойчивых транс-комплексов палладия.

Среди биологических активных комплексов палладия в основном встречаются хлоридные комплексы, так как они чаше проверяются на биологическую активность из-за их большего разнообразия. Хлоридных комплексов получено больше, так как лабораторный синтез комплексов палладия с хлорид ионами требует меньшее количество операций, чем с бромид и иодид ионами. Когда осуществляется синтез не только хлоридных комплексов $(\mathrm{Cl})$, но и бромидных $(\mathrm{Br})$, и иодидных (I); биологические исследования, как правило, выявляют возрастание биологической активности комплексов в ряду $\mathrm{Cl} \rightarrow \mathrm{Br} \rightarrow \mathrm{I}$.

Комплексы палладия с менее устойчивой транс-конформацией проявляют ингибирующую активность к некоторым ферментам. Например, простой комплекс палладия с ацетонитрилом $\left[\mathrm{Pd}\left(\mathrm{CH}_{3} \mathrm{CN}\right)_{2} \mathrm{Cl}_{2}\right]$ проявил умеренную активность в отношении бактериального фермента металло- $\beta$-лактамазы [51]. Более сложный гидразиновый комплекс 13 проявил высокую активность в отношении фермента $\alpha$-гликозидазы [52]. Pd из комплекса 14 проявил ак-<smiles>O=C(NNP(Cl)(Cl)(Cl)NNC(=O)c1ccccc1F)c1ccccc1F</smiles>

13
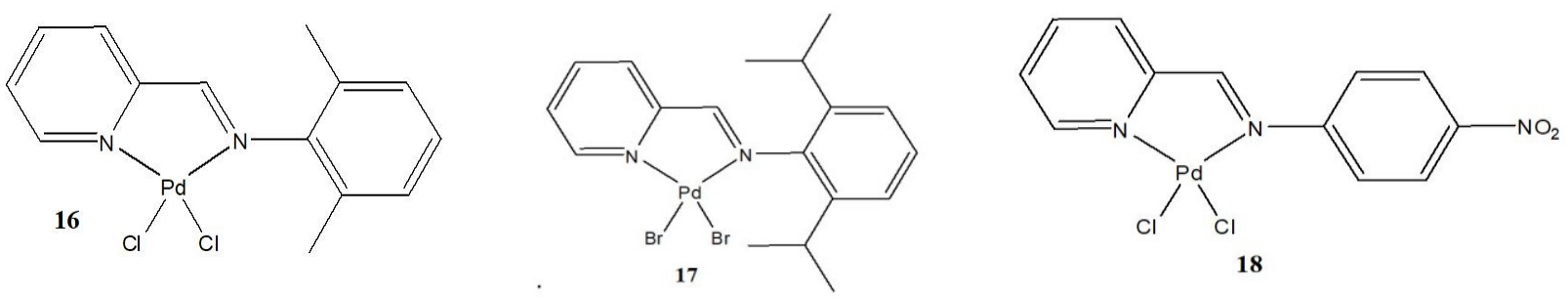

тивность к координации к гистидинам в составе различных белков в физиологических условиях, осуществляя палладиевый катализ гидролиза полипептидной цепи [53].

\section{Бидентатные N-комплексы}

Повышение электронодонорных свойств заместителей, являющихся пиридинами, непосредственно приводит к повышению цитотоксической активности комплексов палладия преимущественно по механизму воздействия на ДНК [19], в то же время биспиридиновый комплекс 15 (бидентатный $\mathrm{N}$-комплекс) продемонстрировал способность ингибировать фермент РНК-полимеразу, полученную из печени самцов крыс линии Wistar [54]. В «ИТХ УрО РАН» синтезированы ряды пиридиниминовых комплексов $\mathrm{Pd}$ [55] (бидентатные $\mathrm{N}$-комплексы), среди которых наиболее активными ингибиторами ферментов МАО являются структуры: 16-18.

Следует отметить, что тут, вопреки общему правилу, бромидные и хлоридные комплексы показали соизмеримую ингибирующую активность, в то время как иодидные не проявили активности. Также установлено отсутствие цитотоксической активности для соединений из рядов 16-18 на клеточной линии НЕК-293 (эмбриональные клетки почки человека). Дополнительно на примере комплекса 17 проведено исследование на острую токсичность на 20 мышах-самцах. На ос-
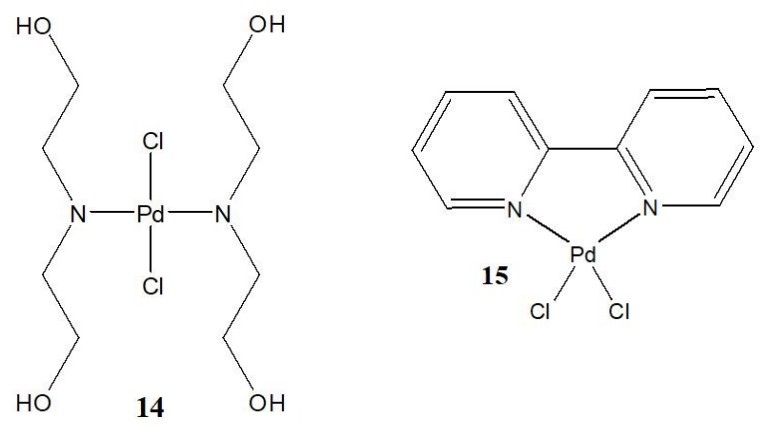
нове полученных данных вещество обладает низкой токсичностью, что позволяет отнести его к классу 4 - «малотоксичные», согласно ГОСТу 12.01.007.76 [55].

Среди бидентатных $\mathrm{N}$-комплексов палладия обнаруживаются комплексы ингибиторы PON1 (например комплекс 19 [56]) и $\mathrm{Na}^{+} / \mathrm{K}^{+}$-АТФазы (например 20 [57]). Комплекс 21 активирует ферменты, связанные с пероксидным окислением, в частности, супероксиддисмутазы, увеличивая продукцию $\mathrm{H}_{2} \mathrm{O}_{2}$ [58], как результат, вещество 21 проявляет большую цитотоксическую активность по отношению к раку молочной железы (клеточная линия MCF-7), чем цисплатин.

\section{Фосфиновые комплексы}

Как правило, фосфиновые комплексы палладия (II) отличаются большей стабильностью в физиологических условиях и меньшей токсичностью К нормальным клеткам [19]. Известно, что для опухолевых клеток характерна повышенная активность топоизомеразы II [60]. Способность фосфиновых комплексов 22 и 23 ингибировать топоизомеразу II объясняет проявление большей цитотоксичности веществ 22 и 23 в сравнении с цисплатином по отношению к опухолевым типам линий: MDA-MB-231, MRC5, DU-145 и PNT2 [59]. Экспериментально установлено, что $\mathrm{Pd}^{\text {II }}$ и $\mathrm{Pt}^{\mathrm{II}}$ связываются с SH-группами бактериального фермента металло- $\beta$-лактамазы, вытесняя из него цинк $\left(\mathrm{Zn}^{\mathrm{II}}\right)$ [51]. Из-за того, что этот фермент ответственен за разрушение антибиотиков пенициллинового ряда, его ингибирование приводит к потере антибиотикорезистентности. Антибиотик Меропенем на примере семейства бактерий Enterobacteriaceae проявил большую антибактериальную активность в присутствии комплекса 24 (источник $\mathrm{Pd}^{\mathrm{II}}$ ), чем в присутствии цисплатина (источник $\mathrm{Pt}^{\mathrm{n}}$ ) [51]. Цис-конформация бис-фосфиновых комплексов является более устойчивой, чем транс-конформация, несмотря на большой $\% \mathrm{~V}_{\text {bar }}$, например для комплекca 25 (ингибитор протеазы ВИЧ-1 [61]), который существует в циис-форме.

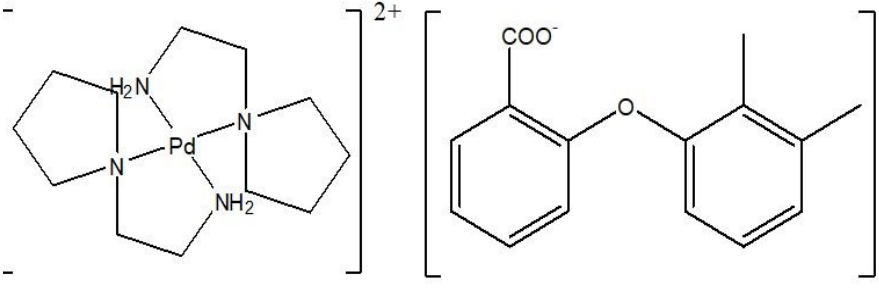

19

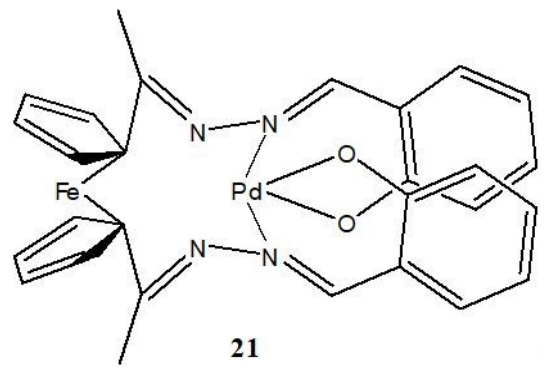

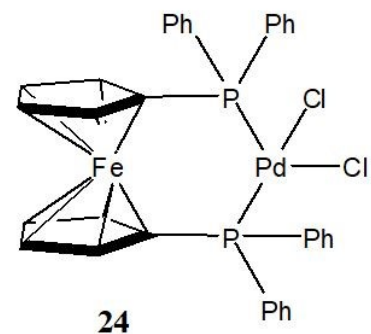

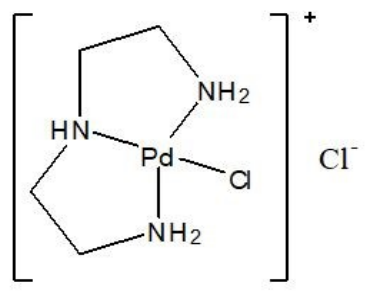

20
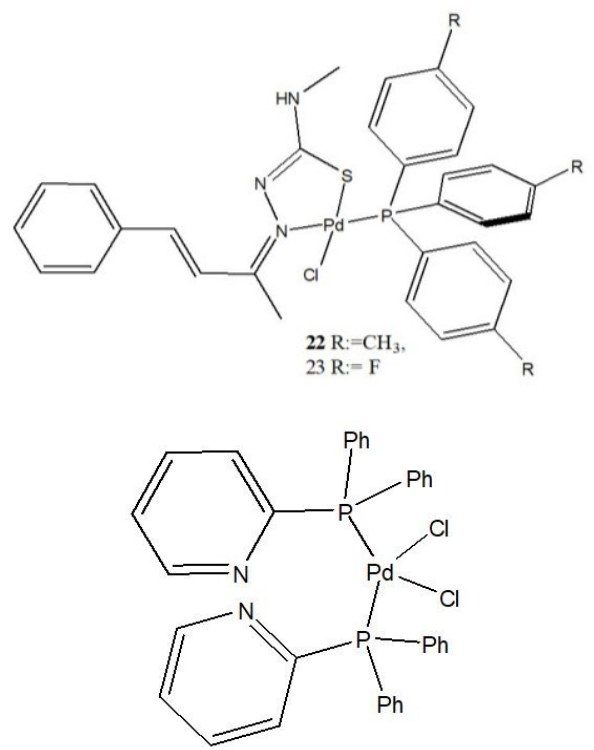

25 


\section{Комплексы с S-лигандом}

Комплекс с S-лигандом 26 запатентован в РФ как ингибитор $\alpha$-амилазы [62], а другой комплекс с S-лигандом 27 является ингибитором селен-содержащего фермента тиоредоксинредуктазы, осуществляющих НАДФН-зависимое восстановление тиоредоксинов (белки с SH-функциональными группами / тиолсодержащие пептиды) [63]. Наличие цитотоксической активности вещества 27 по отношению к таким клеточным линиям, как MCF-7, HT-29, Vero, объясняется повышенной активностью тиоредоксинредуктазы в опухолевых клетках [64].

Установлено, что комплекс 27 не влияет на работу ферментов глутатионредуктазы и глутатионпероксидазы, необходимых для нормального метаболизма, несмотря на то, что их субстратом<smiles>CC(=O)O[Te]1(OCc2c(C)noc2C)(OC(C)=O)CC[SH]1Cc1c(C)noc1C</smiles>

26<smiles></smiles>

28<smiles>CCCCSCc1cccc2c1P(CCCC)Cc1ccccc1-2</smiles>

является тиолсодержащий пептид глутатион [63]. Ранее была выявлена аналогичная селективность для комплекса золота с S-лигандом [65]. Предположено, что модификация тиоредоксинредуктазы осуществляется соединениями палладия

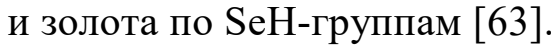

Известен комплекс с S-лигандом 28, ингибирующий НАДФН-зависимую фумаратредуктазу, которая является ферментом возбудителя трипаносомоза Trypanosoma cruzi [66]. Также комплексы 29 и 30 с S-лигандами являются ингибиторами ферментов семейства Old Yellow Enzymes (OYE) [67] и цистеиновой протеазы катепсин Б [68], соответственно. OYE осуществляет разрушение нитрогетероциклических соединений, применяющихся для лечения трипаносомоза.<smiles>CC1=NN2N(C)C(Nc3ccccc3Cl)=N[PH]2(Cl)S1</smiles>

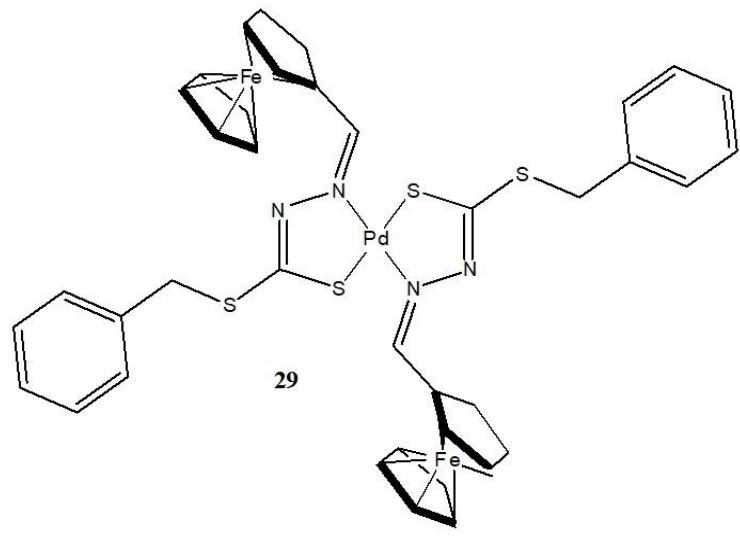




\section{Иминофенольные комплексы}

Иминофенольные комплексы 30 и 31 являются ингибиторами обеих ацетилхолинэстераз $[69,70]$, но для комплекса 30 выявлено умеренное ингибирование глутатионредуктазы, что может говорить о потенциальной гепатотоксичности вещества 30 [71]. По данным молекулярного докинга для вещества $\mathbf{3 1}$ показано связывающее действие за счёт органической части лиганда вне активных сайтов AChE. В ходе эксперимента было установлено, что свободный лиганд комплекса 31 ингибировал $\mathrm{AChE}$ слабее, чем комплекс 31, а ВСhЕ лиганд не ингибировал [69].

Иминофенольные комплексы 32-34 ингибируют ферменты разложения угольной кислоты [72, 73]. Комплексы 32 и 33 различаются расположением метокси- группы, что влияет на селективность: комплекс 32 в большей степени ингибирует hCA I, в то время как 33 - hCA II.

В заключение следует упомянуть работу [74], в которой методами молекулярного докинга показано возможное ингибирование протеазы SARS-CoV-2 комплексом 35.

\section{Заключение}

В результате обзора литературных данных наблюдается широкий интерес к комплексам палладия, используемых в качестве ингибиторов ферментов, участвующих в патогенезе ряда неинфекционных (болезнь Альцгеймера, болезнь Паркинсона, рак, сахарный диабет второго типа) и инфекционных заболеваний (вирусы ВИЧ-1 и SARS-CoV-2, бактерии семейства Enterobacteriaceae, возбудитель трипаносомоза - Trypanosoma cruzi).<smiles></smiles><smiles>CC(C)(C)c1cccc2c1OP1(c3nc(-c4cc5ccccc5oc4=O)cs3)(Nc3cccc(C(C)(C)C)c3O1)N(c1nc(-c3cc4ccccc4oc3=O)cs1)C2</smiles>

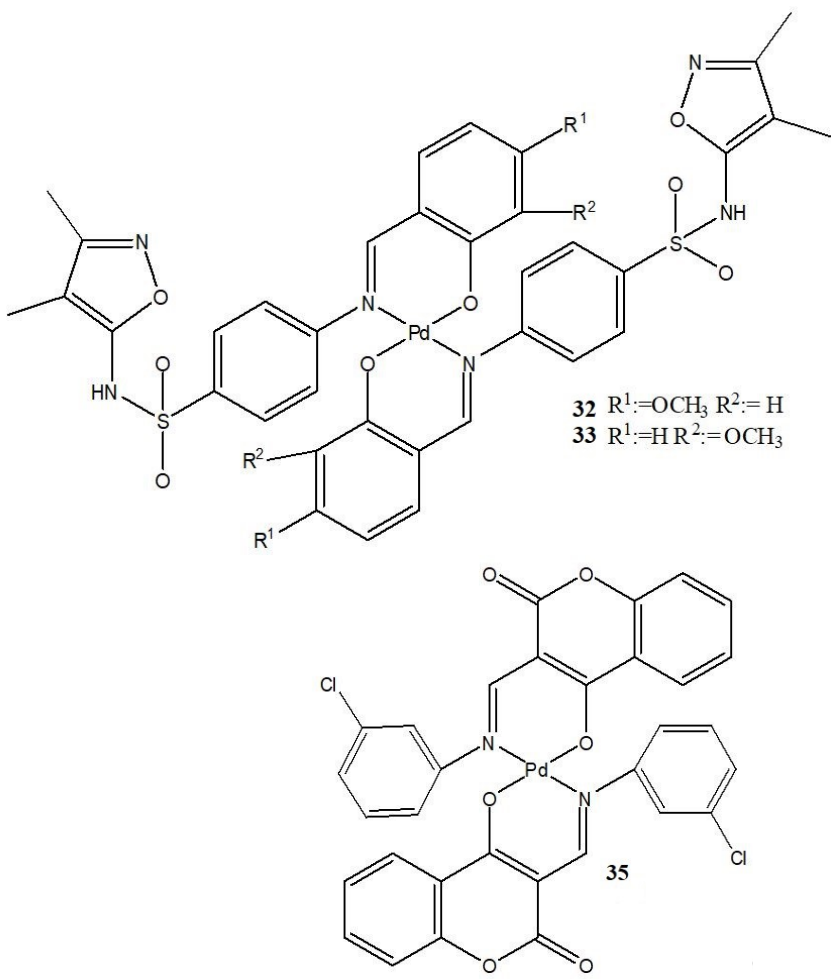

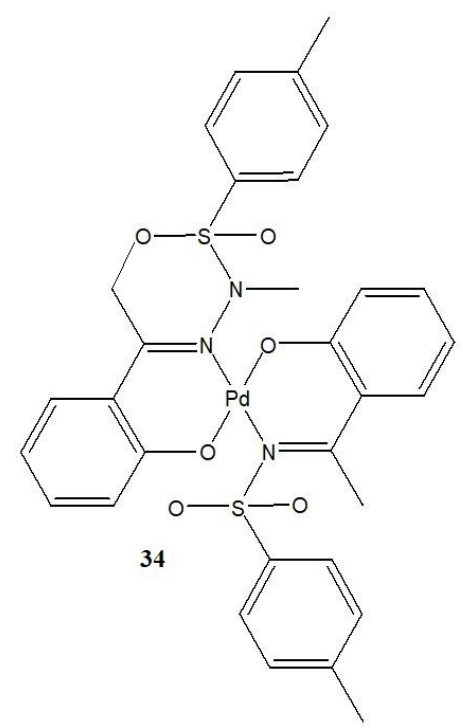


Рассмотренные в данном обзоре комплексы палладия с различными лигандами проявляют ингибирующую активность в отношении широкого разнообразия ферментов. Варьирование лиганда, как и его включения в комплекс, может изменять фермент-ингибирующую активность лиганда в составе комплекса палладия. Следует отметить, что для исследования биологической активности важна как устойчивость комплексов палладия в физиологических усло- виях (буферные растворы), так и биодоступность (водорастворимость и липофильность). Растворимость, реакционная способность, электронные и стерические свойства, а также геометрия комплексов металлов могут контролироваться подбором соответствующего лиганда.

В связи с этим, продолжение исследований по поиску новых биологически активных комплексов палладия может быть перспективным направлением для биомедицинского применения.

\section{Библиографический список}

1. Rosenberg B., VanCamp L., Trosko J.E., Mansour V.H. Platinum Compounds: a New Class of Potent Antitumour Agents // Nature. - 1969. - Vol. 222. - № 5191. - P. 385-386.

2. Kilpin K.J., Dyson P.J. Enzyme inhibition by metal complexes: concepts, strategies and applications // Chemical Science. - 2013. - Vol. 4. - P. 1410-1419.

3. Энциклопедия лекарственных препаратов РЛС [Электронный ресурс] - URL: https://www.rlsnet.ru/ (дата обращения: 26.05.2021).

4. Shu X., Xiong X., Song J, He Ch., Yi Ch. Base Resolution Analysis of Cisplatin-DNA Adducts at the Genome Scale // Angewandte Chemie International Edition. - 2016. - Vol. 55. - № 46. - P. 14246-14249.

5. Egorova K.S., Galushko A.S., Ananikov V.P. Introducing tox Profiles of Chemical Reactions // Angewandte Chemie International Edition. - 2020. - Vol. 59. - № 50. - P. 22296-22305.

6. Dyson P.J., Sava G. Metal based antitumour drugs in the post genomic era // Dalton Transactions. 2006. - Vol. 50. - № 16. - P. 1929-1933.

7. Sava G., Bergamo A., Dyson P.J. Metal based antitumour drugs in the post genomic era: what comes next? // Dalton Transactions. - 2011. - Vol. 40. - № 36. - P. 9069-9075.

8. Ang W.H., Dyson P.J. Classical and Non Classical Ruthenium Based Anticancer Drugs: Towards Targeted Chemotherapy // European Journal of Inorganic Chemistry. - 2006. - Vol. 2006. - № 20. - P. 3993.

9. Timerbaev A.R., Hartinger C.G., Aleksenko S.S., Keppler B.K. Interactions of Antitumor Metallodrugs with Serum Proteins: Advances in Characterization Using Modern Analytical Methodology // Chemical Reviews. - 2006. - Vol. 106. - № 6. - P. 2224-2248.

10. Mulcahy S.P., Li S., Korn R., Xie X., Meggers E. Solid Phase Synthesis of Tris heteroleptic Ruthenium(II) Complexes and Application to Acetylcholinesterase Inhibition // Inorganic Chemistry. - 2008. - Vol. 47. - № 12. - P. 5030-5032.

11. Ong J.X., Yap C.W., Ang W.H. Rational Design of Selective Organoruthenium Inhibitors of Protein Tyrosine Phosphatase 1B // Inorganic Chemistry. - 2012. - Vol. 51. - № 22. - P. 12483-12492.

12. Liu $W$., Gust $R$. Update on metal $\mathrm{N}$ heterocyclic carbene complexes as potential anti-tumor metallodrugs // Coordinational Chemistry Reviews. - 2016. - Vol. 329. - № 15. - P. 191-213.

13. Soman S., Keatinge M., Moein M., Costa M.C., Mortiboys H., Skupin A., Sugunan S., Bazala M., Kuznicki $J$. , Bandmann $O$. Inhibition of the mitochondrial calcium uniporter rescues dopaminergic neurons in pink1-/- zebrafish // European Journal of Neuro science. - 2017. - Vol. 45. - № 4 - P. 528-535.

14. Meggers E. From Conventional to Unusual Enzyme Inhibitor Scaffolds: The Quest for Target Specificity // Angewandte Chemie International Edition. - 2011. - Vol. 50. - № 11. - P. 2442-2448.

15. Che C.-M., Siu F.-M. Metal complexes in medicine with a focus on enzyme inhibition // Current Opinion in Chemical Biology. - 2010. - Vol. 14. - № 2 - P. 255-261.

16. Bruijnincx P.C.A., Sadler P.J. New trends for metal complexes with anticancer activity // Current Opinion in Chemical Biology. - 2008. - Vol. 12. - № 2 - P. 197-206.

17. Louie A.Y., Meade T.J. Metal Complexes as Enzyme Inhibitors // Chemistry Reviews. - 1999. Vol. 99. - № 9 - P. 2711-2734.

18. Meggers E. Targeting proteins with metal complexes // Chemical Communications. - 2009. Vol. 45. - № 9 - P. 1001-1010.

19. Abu Surrah A.S., Al Sa'doni H.H., Abdalla M.Y. Palladium based chemotherapeutic agents: Routes toward complexes with good antitumor activity // Cancer Therapy. - 2008. - Vol. 6. - P. 1-10.

20. Marques M.P.M. Platinum and Palladium Polyamine Complexes as Anticancer Agents: The Structural Factor // International Scholarly Research Notices Spectroscopy. - 2013. - Vol. 2013. - P. 1-29. 
21. Jahromi E.Z., Divsalar A., Saboury A.A., Khaleghizadeh S., Mansouri Torshizi H., Kostova I. Palladium complexes: new candidates for anticancer drugs // Journal of the Iranian Chemical Society. - 2016. Vol. 13. - P. 967-989.

22. Carneiro T.J., Martins A.S., Marques M.P.M., Gil A.M. Metabolic Aspects of Palladium(II) Potential Anti-Cancer Drugs // Frontiers in Oncology. - 2020. - Vol. 10. - №. 590970 DOI: $10.3389 /$ fonc. 2020.590970 .

23. Залевская О.А., Гурьева Я.А., Кучин А.В. Терпеновые лиганды в координационной химии: синтез металлокомплексных соединений, стереохимия, каталитические свойства, биологическая активность // Успехи химии. - 2019. - Т. 88. - № 10 - С. 979-1012.

24. Денисов М.С., Глушков В.A. Биологически активные комплексы палладия(II) и $\mathrm{N}$ гетероциклических ароматических лигандов (обзор литературы) // Вестник Пермского университета. Серия «Химия». - 2018. - Т. 8. - № 4. - Р. 388-411.

25. Serratrice M., Maiore L., Zucca A., Stoccoro S., Landini I., Mini E., Massai L., Ferraro G., Merlino A., Messori L., Cinellu M.A. Cytotoxic properties of a new organometallic platinum(II) complex and its gold(I) heterobimetallic derivatives // Dalton Transactions. - 2016. - Vol. 45. - № 2. - P. 579-590.

26. Mitr I., Mukherjee S., Reddy B. V.P., Misini B., Das P., Dasgupta S., Linert W., Moi S.Ch. Synthesis, biological evaluation, substitution behaviour and DFT study of Pd(II) complexes incorporating benzimidazole derivative // New Journal of Chemistry. - 2018. - Vol. 42. - № 2. - P. 2574-2589.

27. Aghatabay N.M., Somer M., Senel M., Dulger B., Gucin. F. Raman, FT IR, NMR spectroscopic data and antimicrobial activity of bis[ $\mu 2$ (benzimidazol 2 yl) 2-ethanethiolato N,S,S chloro-palladium(II)] dimer, $[(\mu 2 \mathrm{CH} 2 \mathrm{CH} 2 \mathrm{NHNCC} 6 \mathrm{H} 4) \mathrm{PdCl}] 2 \cdot \mathrm{C} 2 \mathrm{H} 5 \mathrm{OH}$ complex // European Journal of Medicinal Chemistry. - 2007. - Vol. 42. - № 8. - P. 1069-1075.

28. Krinulović K.S., Vasić V.M. Interaction of some $\mathrm{Pd}(\mathrm{II})$ complexes with $\mathrm{Na}+\mathrm{K}+\mathrm{ATPase}$ Inhibition, kinetics, prevention and recovery // Journal of Enzyme Inhibition and Medicinal Chemistry. - 2006. Vol. 21. - № 4. - P. 459-465.

29. Sakakibara N., Suzuki K., Kaneta H., Yoshimura Y., Deyama Y., Matsumoto A., Fukuda H. Inhibition of $\mathrm{Na}+\mathrm{K}+$ ATPase by cisplatin and its recovery by 2 mercaptoethanol in human squamous cell carcinoma cells // Anticancer Drugs. - 1999. - Vol. 10. - № 2. - P. 203-211.

30. Tatyanenko L.V., Kotelnikova R.A., Zakharova I.A., Moshkovskii Yu.Sh. On the Mechanism of Platinumand Palladium-Albumin Complexes Interaction with $(\mathrm{Ca} 2+\mathrm{Mg} 2+)$ dependent ATP ase of Sarcoplasmic Reticulum of Skeletal Muscles // Inorganica Chimica Acta. - 1981. - Vol. 56. - P. 89-93.

31. Рапопорт Ж.Ж. Промышленная аллергия и токсикоз (платиноз). - Красноярским гос. мед. ин-т. Красноярск : [б. и.], 1976. - 118 с.

32. Татьяненко Л.В., Соколова Н.В., Мошковский Ю.Ш. Сравнительное исследование механизма действия биологически активных соединений на мембраносвязывающую митохондриальную моноаминоксидазу и $\mathrm{Ca} 2+, \mathrm{Mg} 2+$ зависимую АТФ азу саркоплазматического ретикулума // Вопросы медицинской химии. - 1982. - Т. 28. - № 6. - С. 126-131.

33. Hong R., Li X. Discovery of monoamine oxidase inhibitors by medicinal chemistry approaches // Medicinal Chemistry Communications. - 2019. - Vol. 10. - № 1. - P. 10-25.

34. Chiuccariello L., Houle S., Miller L., Cooke R.G., Rusjan P.M., Rajkowska G., Levitan R.D., Kish S.J., Kolla N.J., Ou X., Wilson A.A., Meyer J.H. Elevated Monoamine Oxidase A Binding During Major Depressive Episodes Is Associated with Greater Severity and Reversed Neurovegetative Symptoms // Neuropsychopharmacology. - 2014. - Vol. 39. - P. 973-980.

35. Денисов М.С., Дмитриев М.В., Ероченко Д.В., Слепухин П.А., Шавкунов С.П., Глушков В.А. Катионно-анионные комплексы PdII с катионом адамантилимидазолия: синтез, структурные исследования и МАО ингибирующая активность // Журнал неорганической химии. - 2019. T. 64. - № 1. - C. 38-50.

36. Albert J., Cadena J.M., González A., Granell J., Solans X., Font-Bardia M. The first NH aldimineorganometallic compound. Isolation and crystal structure // Chemical Communications. 2003. - Vol. 41. - № 4. - P. 528-529.

37. Petrović Z.D., Hadjipavlou-Litina D., Pontiki E., Simijonović D., Petrović V.P. Diethanolamine Pd(II) complexes in bioorganic modeling as model systems of metallopeptidases and soybean lipoxygenase inhibitors // Bioorganic Chemistry. - 2009. Vol. 37. - № 5. - P. 162-166.

38. Ylä-Herttuala S., Rosenfeld E.M., Parthasarathy S., Glass K.C., Sigal E., Witztum L.J., Steinberg D. Colocalization of 15 lipoxygenase mRNA and protein with epitopes of oxidized low density lipoprotein in macrophage rich areas of atherosclerotic lesions // Proceedings of the National Academy of Sciences of the United States of America. - 1990. - Vol. 87 - № 18. - P. 6959-6963.

39. Shultz M.D., Lassig J.P., Gooch M.G. Palladium - a new inhibitor of cellulose activities // Biochemical and biophysical research communications. - 1995. - Vol. 209. - № 3. - P. 1046-1052. 
40. Lassig J.P., Shultz M.D., Gooch M.G., Evans B.R., Woodward J. Inhibition of Cellobiohydrolase I from Trichoderma reesei by Palladium // Archives of Biochemistry and Biophysics. - 1995. Vol. 322. - № 1. - P. 119-126.

41. Abu-Surrah A.S. Development and Current Status of Unconventional Platinum Anticancer Complexes // Mini Reviews in Medicinal Chemistry. - 2007 - Vol.7. - № 2. - P. 203211.

42. Nolan S.P. N-Heterocyclic Carbenes Effective Tool for Organometallic Synthesis. - Wiley vch Verlag $\mathrm{GmbH} \& \mathrm{Co} . \mathrm{KGaA}, 2014 .-543 \mathrm{p}$.

43. Erdemir F., Celepci D.B., Aktaş A., Gök Ye., Kaya R., Taslimi P., Demir Ye., Gulçin İ. Novel 2 aminopyridine liganded $\mathrm{Pd}(\mathrm{II}) \mathrm{N}$ heterocyclic carbene complexes: Synthesis, characterization, crystal structure and bioactivity properties // Bioorganic Chemistry. - 2019. - Vol. 91. - P. 103134-103135.

44. Aktaş A., Celepci D.B., Kaya R., Taslimi P., Gök Y., Aygün M., Gülçin İ. Novel morpholine liganded Pd-based N-heterocyclic carbene complexes: Synthesis, characterization, crystal structure, antidiabetic and anticholinergic properties // Polyhedron. - 2019. - Vol. 159. - P. 345-354.

45. Bal S., Demirci Ö., Şen B., Taslimi P., Aktaş A., Gök Ye., Aygün M., Gülçin İ. PEPPSI type Pd(II)NHC complexes bearing chloro /fluorobenzyl group: Synthesis, characterization, crystal structures, $\alpha$ glycosidase and acetylcholinesterase inhibitory properties // Polyhedron. - 2021. - Vol. 198 - P. 115060-115067.

46. Hansen R.A., Gartlehner G., Webb A.P., Morgan LC., Moore CG., Jonas D.E. Efficacy and safety of donepezil, galantamine, and rivastigmine for the treatment of Alzheimer's disease: A systematic review and meta analysis // Clinical Interventions in Aging. - 2008. - Vol. 3. - № 2. - P. 211-225.

47. Karataş M.O., Çalgın G., Alıcı B., Gökçe B., Gençer N., Tok T.T., Arslan O., Kıllı̧-Clkla I., Özdemir N. Inhibition of paraoxonase 1 by coumarin-substituted $\mathrm{N}$-heterocyclic carbene silver(I), ruthenium(II) and palladium(II) complexes // Applied Organometallic Chemistry. - 2019. - Vol. 33. - № 10. - P. e5130.

48. Wu J., Fang M., Zhou X., Zhu B., Yang Z. Paraoxonase 1 gene polymorphisms are associated with an increased risk of breast cancer in a population of Chinese women. // Oncotarget. - 2017. Vol. 8. - № 15. - P. 25362-25371.

49. Asma M., Badshah A., Ali S., Sohail M., Fettouhi M., Ahmad S., Malik A. Synthesis, Characterization of Mixed Ligand Palladium(II) Complexes of Triphenylphosphine and Anilines and their Enzyme Inhibition Studies against $\beta$ glucuronidase. The Crystal Structure of trans dichloro ( $\mathrm{m}$ chloroaniline) (triphenylphosphine)palladium(II) // Transition Metal Chemistry. - 2006. - Vol. 31. - P. 556-559.

50. Nyhan W.L., Barshop B., Ozand P. Atlas of metabolic diseases second edition. - London, UK: Hodder Arnold, 2005. $-788 \mathrm{p}$.

51. Chen Ch., Sun L. Yu., Gao H., Kang P. W., Li J. Q., Zhen J. B., Ke Wu Yang K.-W. Identification of Cisplatin and Palladium(II) Complexes as Potent Metallo $\beta$ lactamase Inhibitors for Targeting Carbapenem Resistant Enterobacteriaceae // ACS Infectious Diseases. - 2020. - Vol. 6 - № 5. - P. 975-985.

52. Qurrat ul Ain, Ashiq U., Jamal R.A., Saleem M., Mahroof Tahir M. Alpha glucosidase and carbonic anhydrase inhibition studies of Pd(II) hydrazide complexes // Arabian Journal of Chemistry - 2017. Vol. 10. - № 4. - P. 488-499.

53. Petrović Z.D., Djuran M.I., Heinemann F.W., Rajković S., Trifunović S.R. Synthesis, structure, and hydrolytic reaction of trans dichlorobis(diethanolamine N)palladium(II) with $\mathrm{N}$ acetylated $\mathrm{L}$ histidylglycine dipeptide // Bioorganic Chemistry. - 2006. - Vol. 34. - № 5. - P. 225-234.

54. Mital R., Shah G.M., Srivastava T.S., Bhattacharya R.K. The effect of some new platinum (II) and palladium (II) coordination complexes on rat hepatic nuclear transcription in vitro // Life Sciences. 1992. - Vol. 50. - № 11. - P. 781-790.

55. Денисов М.С., Гагарских О.Н., Утушкина Т.А. Пиридиниминовые комплексы палладия (II): синтез и ингибирование моноаминоксидазы // Вестник Пермского университета. Сер. «Химия». - 2021. - Т. 11 - № 1. - С. 30-58.

56. Dilek E., Caglar S., Erdogan K., Caglar B., Sahin O. Synthesis and characterization of four novel palladium(II) and platinum(II) complexes with 1 (2 aminoethyl)pyrrolidine, diclofenac and mefenamic acid: In vitro effect of these complexes on human serum paraoxanasel activity // Journal of Biochemical and Molecular Toxicology. - 2018. - Vol. 32. - № 4. - P. e22043.

57. Krinulović K., Bugarčić Ž., Vrvić M., Krstić D., Vasić V. Prevention and recovery of ( $\mu 3$ diethylentriamino) chloro palladium(II) chloride induced inhibition of $\mathrm{Na} / \mathrm{K} \neg \mathrm{ATPase}$ by SH containing ligands -1 cysteine and glutathione // Toxicology in Vitro. - 2006. - Vol. 20. - № 8. - P. 1292-1299.

58. Hegazy W.H., Al Faiyz Ya.S. Synthesis, characterization, and antitumor activities of $1,1^{\prime}$-diacetylferrocene dihydrazone containing phenolic group and its complexes with $\operatorname{Pd}(\mathrm{II})$ and Pt(II) // Medicinal Chemistry Research. - 2014. - Vol. 23. - № 1. - P. 518-525.

59. Lima M.A., Costa V.A., Franco M.A., de Oliveira G.P., Deflon V.M., Rocha F.V. Palladium(II) complexes bearing thiosemicarbazone and phosphines as inhibitors of DNA Topoisomerase II enzyme: Synthesis, characterizations and biological studies // Inorganic Chemistry Communications. 2020. - Vol. 112. - P. 107708. 
60. Fry A.M., Chresta C.M., Davies S.M., Walker M.C., Harris A.L., Hartley J.A., Masters J.R.W., Hickson I.D. Relationship between topoisomerase II level and chemosensitivity in human tumor cell lines // Cancer Research. - 1991. - Vol.51. - № 24. - P. 6592-6595.

61. Gama N.H., Elkhadir A.Y.F., Gordhan B.G., Kana B.D., Darkwa J., Meyer D. Activity of phosphino palladium(II) and platinum(II) complexes against HIV 1 and Mycobacterium tuberculosis // Biometals. - 2016. - Vol. 29. - P. 637-650.

62. Рахимова А.В., Салаватович А.Н., Анварович 3.Р., Габдурахманов И.А., Валиулловна К.Р., Меметович Дж.У. Патент РФ № 2709512 от 14.02.2019 г.

63. Parrilha G.L., Ferraz K.S.O., Lessa J.A., Oliveira K.N., Rodrigues B.L., Ramos J.P., Souza-Fagundes E.M., Ott I., Beraldo H. Metal complexes with 2 acetylpyridine N(4) orthochlorophenylthiosemicarbazone: Cytotoxicity and effect on the enzymatic activity of thioredoxin reductase and glutathione reductase // European Journal of Medicinal Chemistry. - 2014. Vol. 84. - № 12. - P. 537-544.

64. Becker K., Gromer S., Schirmer R.H., Müller S. Thioredoxin reductase as a pathophysiological factor and drug target // European Journal of Biochemistry. - 2000. - Vol. 267. - № 20. - P. 6118-6125.

65. Ott I. On the medicinal chemistry of gold complexes as anticancer drugs // Coordination Chemistry Reviews. - 2009. - Vol. 253. - № 11 12. - P. 1670-1681.

66. Vieites M. , Smircich P., Parajón Costa B., Rodríguez J., Galaz V., Olea Azar C., Otero L., Aguirre G., Cerecetto H., González M., Gómez-Barrio A., Garat B., Gambino D. Potent in vitro anti Trypanosoma cruzi activity of pyridine 2 thiol $\mathrm{N}$ oxide metal complexes having an inhibitory effect on parasite-specific fumarate reductase // JBIC Journal of Biological Inorganic Chemistry. - 2008. Vol. 13. - № 5. - P. 723-735.

67. Carneiro Z.A., Lima J.C., Lopes C.D.,Gaspari A.P.S., Albuquerque S., Dinelli L.R., Veloso Silva L.L.W., Paganelli M.O., Libardi S.H., Oliveira C.G., Deflon V.M., Oliveira R.J., Borges J.C., Maia P.I.S. Heterobimetallic nickel(II) and palladium(II) complexes derived from S benzyl $\mathrm{N}$ (ferrocenyl) methylenedithiocarbazate: Trypanocidal activity and interaction with Trypanosoma cruzi Old Yellow Enzyme (TcOYE) // European Journal of Medicinal Chemistry. 2019. - Vol. 180. - № 15. - P. 213-223.

68. Fricker S.P., Mosi R.M., Cameron B.R., Baird I., Zhu Yo., Anastassov V., Cox J., Doyle P.S., Hansell E., Lau G., Langille J., Olsen M., Qin L., Skerlj R., Wong R.S.Y., Santucci Z., McKerrow J.H. Metal compounds for the treatment of parasitic diseases // Journal of Inorganic Biochemistry. - 2008. - Vol. 102. - № 10. - P. 1839-1845.

69. Buldurun K., Turan N., Bursal E., Aras A., Mantarcı A., Çolak N., Türkan F., Gülçin İ. Synthesis, characterization, powder $\mathrm{X}$ ray diffraction analysis, thermal stability, antioxidant properties and enzyme inhibitions of M(II) Schiff base ligand complexes // Journal of Biomolecular Structure and Dynamics. - 2020. - Doi: 10.1080/07391102.2020.1802340.

70. Şahin Ö, Özdemir Ü.Ö., Seferoğlu N., Adem Ş., Seferoğlu Z. Synthesis, characterization, molecular docking and in vitro screening of new metal complexes with coumarin Schiff base as anticholine esterase and antipancreatic cholesterol esterase agents // Journal of Biomolecular Structure and Dynamics. - 2021. Doi: 10.1080/07391102.2020.1858163.

71. Türkan F., Huyut Z., Atalar M.N. The toxicological impact of some avermectins on human erythrocytes glutathione $\mathrm{S}$ transferase enzyme // Journal of Biochemical and Molecular Toxicology. 2018. - Vol. 32. - № 10. - P. e22205.

72. Alyar S., Sen C., Alyar H., Adem S.., Kalkanci A., Ozdemir U.O. Synthesis, characterization, antimicrobial activity, carbonic anhydrase enzyme inhibitor effects, and computational studies on new Schiff bases of Sulfa drugs and their Pd(II), Cu(II) complexes // Journal of Molecular Structure. 2018. - Vol. 1171. - № 5. - P. 214-222.

73. Özbek N., Alyar S., Memmi B.K., Gündüzalp A.B., Bahçeci Z., Alyar H. Synthesis, characterization, computational studies, antimicrobial activities and carbonic anhydrase inhibitor effects of 2 hydroxyacetophenone $\mathrm{N}$ methyl $\mathrm{p}$ toluenesulfonylhydrazone and its $\mathrm{Co}(\mathrm{II}), \mathrm{Pd}(\mathrm{II}), \mathrm{Pt}(\mathrm{II})$ complexes // Journal of Molecular Structure - 2017. - Vol. 1127. - P. 437-448.

74. Milenković D.A., Dimić D.S., Avdovićac E.H., Marković Z.S. Several coumarin derivatives and their $\mathrm{Pd}(\mathrm{II})$ complexes as potential inhibitors of the main protease of SARS CoV 2, an in silico approach // RSC Advances. - 2020. - Vol. 2020. - № 58. - P. 35099-35108. 


\title{
PALLADIUM-BASED ENZYME INHIBITORS (REVIEW)
}

\author{
M.S. Denisov \\ Institute of Technical Chemistry UB RAS
}

\section{For citation:}

Denisov M.S. Palladium-based enzyme inhibitors (review) // Perm Federal Research Center Journal. - 2021. - № 4. P. 6-18. https://doi.org/10.7242/2658-705X/2021.4.1

This review collects literature data from 1969 to 2021 aimed at studying the influence of the coordination environment of palladium in complex metal compounds on the ability of palladium to inhibit enzymes. In particular, selective inhibition of enzymes and inhibition of enzymes as a mechanism of toxicity has been demonstrated. Inorganic, trans-coordinated, bidentate $\mathrm{N}, \mathrm{S}$, phosphine, and iminophenol complexes are considered. Palladium compounds have been shown to inhibit enzymes involved in the pathogenesis of a number of diseases, such as Alzheimer's disease, Parkinson's disease, atherosclerosis, and type 2 diabetes mellitus. Palladium compounds can be used in targeted cancer therapy as inhibitors of tumor enzymes. Palladium compounds can also be used as inhibitors of the enzymes of the HIV-1 and SARS-CoV-2 viruses, trypanosomiasis, putrefactive microbes and other microorganisms. At the same time, some palladium complexes can be toxic and allergens due to the inhibition of the beneficial enzymes. We have noted that the further search for biomedical applications of palladium compounds is a promising direction for biomedicine.

Keywords: palladium, enzyme inhibitors.

\section{Сведения об авторе}

Денисов Михаил Сергеевич, кандидат химических наук, научный сотрудник, Институт технической химии УрО РАН - филиал Пермского федерального исследовательского центра УрО РАН («ИТХ УрО РАН»), 614013, Россия, г. Пермь, ул. Академика Королёва, 3; e-mail: denisov.m@itcras.ru 